\title{
Association of daily tar and nicotine intake with incident myocardial infarction: Results from the population-based MONICA/KORA Augsburg Cohort Study 1984 - 2002
}

Qiu-Li Zhang ${ }^{1 \dagger}$, Jens Baumert ${ }^{1 *+}$, Karl-Heinz Ladwig ${ }^{1}$, H-Erich Wichmann ${ }^{2,3}$, Christa Meisinger ${ }^{1}$ and Angela Döring ${ }^{1,2}$

\begin{abstract}
Background: Cigarette smoking has been shown to be one of the most important risk factors for cardiovascular diseases. However, little is known about cumulative effects of daily tar and nicotine intake on the risk of incident myocardial infarction (MI) so far. To bridge this gap, we conducted an analysis in a large prospective study from Southern Germany investigating associations of daily tar and nicotine intake with an incident Ml event.

Methods: The study was based on 4,099 men and 4,197 women participating in two population-based MONICA Augsburg surveys between 1984 and 1990 and followed up within the KORA framework until 2002. During a mean follow-up of 13.3 years, a number of 307 men and 80 women developed an incident Ml event. Relative risks were calculated as hazard ratios (HRs) estimated by Cox proportional hazards models adjusted for cardiovascular risk factors.

Results: In the present study, male regular smokers consumed on average more cigarettes per day than female regular smokers (20 versus 15) and had a higher tar and nicotine intake per day. In men, the Ml risk compared to never-smokers increased with higher tar intake: HRs were 2.24 (95\% Cl 1.40-3.56) for 1-129 mg/day, 2.12 (95\% Cl 1.37-3.29) for 130-259 mg/day and 3.01 ( $95 \%$ Cl 2.08-4.36) for $\geq 260 \mathrm{mg} /$ day. In women, the corresponding associations were comparable but more pronounced for high tar intake (HR 4.67, 95\% Cl 1.76-12.40). Similar associations were observed for nicotine intake.
\end{abstract}

Conclusions: The present study based on a large population-based sample adds important evidence of cumulative effects of tar and nicotine intake on the risk of incident Ml. Even low or medium tar and nicotine intake revealed substantial risk increases as compared to never-smokers. Therefore, reduction of tar and nicotine contents in cigarettes cannot be seen as a suitable public health policy in preventing myocardial infarction.

\section{Background}

Cigarette smoking is a central issue in public health policy as it has been shown to be associated with an elevated risk of various cardiovascular diseases and types of cancer $[1,2]$. Smoking has been determined as one of the most important risk factors for myocardial infarction

\footnotetext{
* Correspondence: baumert@helmholtz-muenchen.de

† Contributed equally

'Institute of Epidemiology II, Helmholtz Zentrum München, German Research Center for Environmental Health, Ingolstädter Landstrasse 1, 85764 Neuherberg, Germany

Full list of author information is available at the end of the article
}

(MI) [3-5], but it was shown that smoking cessation can reduce this risk [6]. Many countries and international agencies have made great efforts to change smoking behaviour and to encourage smokers to quit smoking, e. g. by preventing initiation of tobacco use, promoting cessation among adolescents and adults, or banning advertising and promotions [7]. The need for regulation and legislation on limits of harmful substances, including tar and nicotine content in cigarettes, has recently drawn a lot of attention. The European Union recommended that the upper limit of tar content should be

\section{() Biomed Central}


decreased from $12 \mathrm{mg}$ to $10 \mathrm{mg}$. Such regulatory efforts might modify cigarette design in tobacco industry and might be seen as a further focus in smoking preventing policy, although it as been shown that even so-called "light" cigarettes with reduced tar and nicotine yield might have adverse effects on the health status.

However, little is known on how lower tar and nicotine contents in cigarettes can change overall smoking behaviour and subsequently have an affect on the risk for smoking-related diseases like MI. The associations between the number of smoked cigarettes and quantity of tar and nicotine yield of smoked cigarette remains unclear. Several studies have investigated effects of low yield cigarette by reductions of tar and nicotine emissions on the MI risk, however results are inconclusive [8-12].

To bridge this gap, the present analysis based on a population-based prospective study was carried out to investigate the extent of cumulative effects of daily tar and nicotine intake on the risk of an incident fatal or non-fatal MI event including coronary death. We would like to give an answer to the question whether a reduction of tar and nicotine contents in cigarettes might be seen as a suitable public health policy in preventing the incidence of a MI. Due to sex-specific differences in smoking behaviour and MI incidence, we conduct all analyses separately in men and women.

\section{Methods}

\section{Study design and study population}

The present study was derived from the populationbased MONICA (Monitoring Trends and Determinants in Cardiovascular Diseases)/KORA (Cooperative Health Research in the Region of Augsburg) Augsburg surveys conducted between 1984 and 1995 [5,13]. The World Health Organization (WHO) MONICA Project was initiated in the early 1980s in 26 countries to monitor the risk factors for cardiovascular diseases, such as hypertension, smoking, hypercholesterolemia and obesity [14]. The MONICA Augsburg Study, a part of the multinational WHO MONICA project, was initiated in 1984 in the city of Augsburg and two adjacent counties in southern Germany. The study was approved by the local authorities: The MONICA surveys S1 and S2 with the baseline examination were approved by the data protection commission following the rules at the time of the examinations (1984/85 and 1989/90). The follow-up examinations within the KORA framework were approved by the ethics committee of the Bavarian Medical Association. All participants provided a written informed consent.

Overall, a number of 8,802 persons participated in the first survey (S1) conducted in 1984/85 (age range 25 to 64 years, response $79 \%$ ) or in the second survey (S2) conducted in 1989/90 (age range 25 to 74 years, response 77\%). After excluding 506 participants with a history of MI or with incomplete information on any of the considered variables, the study population of the present analysis comprised of 8,296 subjects (4,099 men and 4,197 women).

Baseline information on socio-demographical and lifestyle characteristics as well as medical examinations including collection of a nonfasting venous blood sample was assessed by trained medical staff in a standardized manner following the WHO MONICA recommendations [15].

\section{Definition of incident MI}

Within the framework of KORA study participants were followed up until 2002. The outcome incident MI was defined as the first event of a non-fatal or fatal MI including coronary death before the age of 75 years and was assessed by the MONICA/KORA Augsburg coronary event registry [16]. Until December 2000, the diagnosis of a major non-fatal MI event was based on the MONICA algorithm taking into account symptoms, cardiac enzymes and electrocardiography (ECG) changes. Since January 1, 2001 MI was diagnosed according to ESC and ACC criteria. Vital status of all cohort members was assessed regularly through the population registries. Deaths from MI were validated by autopsy reports, death certificates, chart review, and information from the last treating physician.

Mean duration of follow-up was 13.3 years (standard deviation (SD) 4.4) and ranged from 0.03 to 18.2 years. During the follow-up period, a number of 307 men and 80 women developed an incident MI event.

\section{Definition of smoking status, tar and nicotine intake}

Smoking status was assessed by a face-to-face interview by asking "Do you currently smoke cigarettes?". In case of answering "yes", participants were further asked if they smoke regularly or occasionally; in case of answering "no", participants were asked "Have you ever smoked cigarettes?". Moreover, the average amount of cigarettes smoked per day among regular smokers was assessed in the questionnaire by the question "How many cigarettes do you smoke on average per day?" and age at smoking onset by the question "How old have you been when you started to smoke cigarettes?".

Participants were classified into four categories: regular smokers, occasional smokers, ex-smokers and neversmokers. Regular smokers are defined as those who reported to smoke currently at least one cigarette per day; while occasional smokers smoked less than one cigarette per day on average. Ex-smokers are those subjects who smoked cigarettes daily before the time of baseline examination but not currently. Never-smokers 
reported to have not consumed any cigarettes before the time of baseline examination. The number of cigarettes smoked on average per day (cig/day) was divided into light smokers (1-19 cig/day) and heavy smokers $(\geq 20$ cig/day).

Information on tar and nicotine contents of cigarette for each brand was obtained from annual reports by the respective cigarette manufactures. Among the regular smokers, nicotine intake per day (mg/day) was calculated by multiplying the nicotine yield per cigarette smoked with the number of cigarettes smoked per day, and tar intake per day (mg/day) was calculated by multiplying the tar yield per cigarette smoked with the number of cigarettes smoked per day. Using tertiles of the distribution of nicotine yield per cigarette, nicotine intake per day was divided into groups of low $(\leq 8 \mathrm{mg} /$ day), medium (9 - $16 \mathrm{mg} /$ day), and high nicotine intake per day ( $\geq 17 \mathrm{mg} /$ day) among regular smokers. Using tertiles of the distribution of tar yield per cigarette, tar intake per day then was grouped into groups of low ( $\leq 129 \mathrm{mg} /$ day), medium (130 - $259 \mathrm{mg} /$ day), and high tar intake per day ( $\geq 260 \mathrm{mg} /$ day) among regular smokers.

\section{Definition of cardiovascular risk factors}

Venipuncture was performed on the sitting subjects with minimal tourniquet use. Further blood handling followed strict standardization. Total serum cholesterol and high density lipoprotein cholesterol (HDL-C) were measured by enzymatic methods (CHOD-PAP, Boehringer Mannheim, Germany). HDL-C was precipitated with phosphotungstic acid and magnesium ions. For the present analyses, we used the ratio of total cholesterol and HDL$\mathrm{C}$ (total cholesterol/HDL-C). Alcohol intake was assessed by a recall method and alcohol consumption was calculated in grams/day (g/day). Alcohol consumption was classified into three categories: non-drinkers $(0 \mathrm{~g} / \mathrm{d})$, intake of 0.1-39.9 g/day and $\geq 40.0 \mathrm{~g} /$ day for men and intake of 0.1-19.9 g/day and $\geq 20.0 \mathrm{~g} /$ day for women. To assess physical activity, participants were considered as active during leisure time if they regularly participated in sports in summer and in winter and if they were active for at least one hour per week in either season. All other participants were considered as inactive. Actual hypertension was defined as blood pressure values $\geq 140 / 90$ $\mathrm{mmHg}$ and/or use antihypertensive medication, given that the subjects were aware of being hypertensive. Diabetes was defined if participants reported a history of diabetes or if they reported use of anti-diabetic medication.

\section{Statistical analysis}

We conducted a descriptive analysis by baseline characteristics and risk factors separately for men and women to give a description of the study population. Multivariable analyses were performed by Cox proportional hazards models to assess the effect of smoking habits, tar and nicotine intake on incident MI with controlling for potential confounding by other cardiovascular risk factors. Never-smokers were chosen as reference category. All models were calculated separately for men and women. A first basic model was adjusted for age (continuous) and survey (S1 or S2); a second multivariable model was adjusted additionally for the following variables: alcohol consumption (men: 0, 1-39, $\geq 40$ g/day, women: $0,1-19, \geq 20 \mathrm{~g} /$ day), actual hypertension (yes or no), ratio of total cholesterol and HDL-C $(<3.0,3.0-5.4$, $\geq 5.5$ ), physical inactivity (yes or no) and history of diabetes (yes or no). Results are presented as hazard ratio (HR) with 95\% confidence interval (95\% CI). Significance tests were 2-tailed. For all statistical analysis a $\mathrm{p}$ value less than 0.05 was considered to be statistically significant. The evaluations were performed with the statistical software package SAS (Version 9.1, SAS-Institute Inc., Cary, NC, USA).

\section{Results}

\section{Description of study population}

Overall, more men (30.4\%) than women (17.9\%) smoked regularly in the present study population, while a higher percentage of women were never-smokers compared to men (28.8\% of men, $62.3 \%$ of women). Male regular smokers consumed on average 20 cigarettes per day compared to female regular smokers with a mean of 15 cigarettes per day. Moreover, the mean intake was higher in male than in female smokers both for tar (264 versus $162 \mathrm{mg} /$ day) and nicotine (17 versus $11 \mathrm{mg} /$ day). Therefore, among male regular smokers, the majority belonged to the high tar and nicotine intake group (52.9\% and $43.1 \%)$, while female regular smokers had more frequently a low tar and nicotine intake $(43.1 \%$ and $48.9 \%)$.

The distribution of baseline characteristics and risk factors according to smoking status including tar and nicotine intake per day are presented in table 1 for men and table 2 for women. The mean age at baseline examination was higher in the low tar or nicotine intake group than in the high tar or nicotine intake group. With higher tar or nicotine intake, the cardiovascular risk factors total cholesterol/HDL-C, alcohol consumption and physical inactivity increased and actual hypertension decreased in mean or proportion which was more pronounced in men than in women. In both sexes, smokers with a high tar and nicotine intake per day started to smoke at an earlier age and had a shorter duration of smoking than those with low or medium tar and nicotine intake per day. 
Table 1 Baseline characteristics and risk factors according to smoking status including tar and nicotine intake (mg/ day) among men ( $n=4,099$ )

\begin{tabular}{|c|c|c|c|c|c|c|c|c|c|}
\hline \multirow[t]{2}{*}{ Characteristics } & \multirow{2}{*}{$\begin{array}{l}\text { Never- } \\
\text { smokers }\end{array}$} & \multirow{2}{*}{$\begin{array}{c}\text { Ex- } \\
\text { smokers }\end{array}$} & \multirow{2}{*}{$\begin{array}{l}\text { Occasional } \\
\text { smokers }\end{array}$} & \multicolumn{3}{|c|}{ Tar intake (mg/day) } & \multicolumn{3}{|c|}{ Nicotine intake (mg/day) } \\
\hline & & & & $\begin{array}{l}\text { Low } \\
(\leq 129)\end{array}$ & $\begin{array}{l}\text { Medium } \\
(130-259)\end{array}$ & $\begin{array}{l}\text { High } \\
(\geq 260)\end{array}$ & $\begin{array}{l}\text { Low } \\
(\leq 8)\end{array}$ & $\begin{array}{l}\text { Medium } \\
(9-16)\end{array}$ & $\begin{array}{l}\text { High } \\
(\geq 17)\end{array}$ \\
\hline No. of participants (n) & 1,181 & 1,532 & 141 & 236 & 350 & 659 & 290 & 418 & 537 \\
\hline Mean age (years) & 46.0 & 50.9 & 43.9 & 49.3 & 44.0 & 42.2 & 48.2 & 43.7 & 42.1 \\
\hline Mean total cholesterol/HDL-C & 4.8 & 5.1 & 4.8 & 5.0 & 5.2 & 5.5 & 5.0 & 5.3 & 5.6 \\
\hline Mean alcohol consumption (g/day) & 26.1 & 32.4 & 36.5 & 34.3 & 33.1 & 45.0 & 34.5 & 36.5 & 44.8 \\
\hline Physical inactivity (\%) & 57.1 & 55.1 & 56.0 & 60.6 & 56.3 & 67.7 & 56.9 & 58.4 & 70.2 \\
\hline Actual hypertension (\%) & 40.6 & 47.9 & 36.9 & 47.9 & 35.7 & 36.9 & 43.5 & 37.6 & 36.9 \\
\hline Diabetes (\%) & 2.5 & 5.2 & 2.8 & 4.7 & 4.3 & 3.2 & 4.1 & 4.1 & 3.4 \\
\hline Mean age at smoking onset (years) & - & - & 18.9 & 19.5 & 18.1 & 17.6 & 19.4 & 18.0 & 17.6 \\
\hline Mean duration of smoking (years) & - & - & 25.7 & 30.5 & 26.5 & 25.2 & 29.5 & 26.4 & 25.2 \\
\hline
\end{tabular}

Risk of incident MI by smoking habits and number of cigarettes per day

The association between smoking habits and the risk of an incident MI event with two categories for regular smokers classified by the number of cigarettes smoked per day is shown in the first part of table 3 for men and of table 4 for women. Compared to never-smokers, male regular smokers had a risk-factor-adjusted HR of 2.34 (95\% CI 1.60-3.43) when consuming 1-19 cigarettes per day and of 2.71 (95\% CI 1.88-3.89) when consuming 20 or more cigarettes per day. In women, the respective HRs were 1.68 (95\% CI 0.79-3.57) and 3.86 (95\% CI 1.57-9.50) showing a strong risk increase compared to never-smokers when consuming 20 or more cigarettes per day. These effects might indicate that the risk associated with increasing numbers of cigarettes was greater in women. Risks for ex- and occasional smokers were lower in men than in women compared to regular smokers. In women, the HR for smokers consuming 1-19 cigarettes per day was higher than for ex-smokers $(1.93,95 \%$ CI 1.07-3.47) and comparable to occasional smokers (1.60, 95\% 0.39-6.65).
Risk of incident MI by tar and nicotine yield per cigarette The MI risk increased in both sexes with rising tar or nicotine yield per cigarette per day: Compared to neversmokers, male regular smokers consuming cigarettes with $\geq 13 \mathrm{mg}$ tar yield per cigarette showed a HR of 3.12 (95\% CI 2.23-4.36) and with $\geq 0.8 \mathrm{mg}$ nicotine yield per cigarette showed a HR of 3.01 (95\% CI 2.164.19) in the multivariable-adjusted model. Similar results were found for women with higher HRs in the elevated tar or nicotine group.

Risk of incident MI by tar and nicotine intake per day Regarding the MI risk by tar intake per day estimated by a multivariable-adjusted model compared to never-smokers revealed an risk increase in male regular smokers shown by a HR of 2.24 (95\% CI 1.40-3.56) for 1-129 $\mathrm{mg} /$ day and 3.01 (95\% CI 2.08-4.36) for $\geq 260 \mathrm{mg} /$ day. In female regular smokers, the corresponding associations were attenuated for low tar intake (HR 1.31, 95\% CI 0.47-3.65), but more pronounced for smokers having a high tar intake (HR 4.67, 95\% CI 1.76-12.40).

Table 2 Baseline characteristics and risk factors according to smoking status including tar and nicotine intake (mg/ day) among women $(n=4,197)$

\begin{tabular}{|c|c|c|c|c|c|c|c|c|c|}
\hline \multirow[t]{2}{*}{ Characteristics } & \multirow{2}{*}{$\begin{array}{c}\text { Never- } \\
\text { smokers }\end{array}$} & \multirow{2}{*}{$\begin{array}{c}\text { Ex- } \\
\text { smokers }\end{array}$} & \multirow{2}{*}{$\begin{array}{l}\text { Occasional } \\
\text { smokers }\end{array}$} & \multicolumn{3}{|c|}{ Tar intake (mg/day) } & \multicolumn{3}{|c|}{ Nicotine intake (mg/day) } \\
\hline & & & & $\begin{array}{l}\text { Low } \\
(\leq 129)\end{array}$ & $\begin{array}{c}\text { Medium } \\
(130-259)\end{array}$ & $\begin{array}{c}\text { High } \\
(\geq 260)\end{array}$ & $\begin{array}{l}\text { Low } \\
(\leq 8)\end{array}$ & $\begin{array}{c}\text { Medium } \\
(9-16)\end{array}$ & $\begin{array}{l}\text { High } \\
(\geq 17)\end{array}$ \\
\hline No. of participants (n) & 2,613 & 693 & 139 & 324 & 238 & 190 & 368 & 235 & 149 \\
\hline Mean age (years) & 50.0 & 44.0 & 39.8 & 42.9 & 40.6 & 38.8 & 42.5 & 40.0 & 39.6 \\
\hline Mean total cholesterol/HDL-C & 4.0 & 3.7 & 3.6 & 3.9 & 4.0 & 4.1 & 4.0 & 4.0 & 4.0 \\
\hline Mean alcohol consumption (g/day) & 8.4 & 11.0 & 12.8 & 10.5 & 12.3 & 13.8 & 10.9 & 12.9 & 12.7 \\
\hline Physical inactivity (\%) & 66.3 & 55.0 & 50.4 & 61.7 & 63.5 & 71.6 & 62.8 & 61.3 & 75.2 \\
\hline Actual hypertension (\%) & 35.5 & 23.2 & 21.6 & 21.3 & 18.9 & 17.9 & 20.9 & 17.5 & 20.1 \\
\hline Diabetes (\%) & 3.8 & 3.2 & 2.2 & 0.9 & 0.8 & 1.1 & 1.1 & 0.4 & 1.3 \\
\hline Mean age at smoking onset (years) & - & - & 22.0 & 21.5 & 19.3 & 18.4 & 21.3 & 19.2 & 18.4 \\
\hline Mean duration of smoking (years) & - & - & 18.4 & 22.1 & 21.8 & 21.0 & 21.9 & 21.4 & 21.9 \\
\hline
\end{tabular}


Table 3 Risk of incident myocardial infarction by number of cigarettes per day (cig/day), tar and nicotine yield per cigarette (mg/cig) and tar and nicotine intake per day (mg/day) in men: Hazard ratio (HR) and $95 \%$ confidence interval $(95 \% \mathrm{Cl})$

\begin{tabular}{|c|c|c|c|c|}
\hline Smoking habits & $\begin{array}{l}\text { Number of } \\
\text { participants } \\
\text { (N) }\end{array}$ & $\begin{array}{l}\text { Number of } \\
\text { events } \\
\text { (N) }\end{array}$ & $\begin{array}{c}\text { Age- and survey-adjusted } \\
\text { model* } \\
\text { HR }(95 \% \mathrm{Cl})\end{array}$ & $\begin{array}{c}\text { MI risk factor-adjusted } \\
\text { model }^{+} \\
\text {HR }(95 \% \mathrm{Cl})\end{array}$ \\
\hline Never-smokers $^{++}$ & 1,181 & 53 & 1.00 & 1.00 \\
\hline Ex-smokers & 1,532 & 117 & $1.31(0.94-1.81)$ & $1.26(0.90-1.75)$ \\
\hline Occasional smokers & 141 & 7 & $1.14(0.52-2.50)$ & $1.15(0.52-2.53)$ \\
\hline \multicolumn{5}{|l|}{ Regular smokers } \\
\hline \multicolumn{5}{|l|}{ Number of cigarettes smoked per day } \\
\hline Light smokers (1 - 19 cig/day) & 503 & 54 & $2.54(1.74-3.71)$ & $2.34(1.60-3.43)$ \\
\hline Heavy smokers ( $\geq 20$ cig/day) & 742 & 76 & $3.13(2.20-4.45)$ & $2.71(1.88-3.89)$ \\
\hline \multicolumn{5}{|l|}{ Tar yield per cigarette ${ }^{\#}$} \\
\hline $1-12 \mathrm{mg} / \mathrm{cig}$ & 274 & 29 & $2.21(1.40-3.47)$ & $2.05(1.30-3.24)$ \\
\hline$\geq 13 \mathrm{mg} / \mathrm{cig}$ & 971 & 101 & $3.12(2.23-4.36)$ & $2.73(1.94-3.84)$ \\
\hline \multicolumn{5}{|l|}{ Nicotine yield per cigarette ${ }^{\#}$} \\
\hline $0.1-0.7 \mathrm{mg} / \mathrm{cig}$ & 229 & 26 & $2.36(1.48-3.78)$ & $2.20(1.37-3.52)$ \\
\hline$\geq 0.8 \mathrm{mg} / \mathrm{cig}$ & 1,016 & 104 & $3.01(2.16-4.19)$ & $2.64(1.88-3.71)$ \\
\hline \multicolumn{5}{|l|}{ Tar intake per day ${ }^{\#}$} \\
\hline $1-129 \mathrm{mg} /$ day & 236 & 27 & $2.36(1.48-3.75)$ & $2.24(1.40-3.56)$ \\
\hline 130 - 259 mg/day & 350 & 33 & $2.36(1.53-3.65)$ & $2.12(1.37-3.29)$ \\
\hline$\geq 260$ mg/day & 659 & 70 & $3.49(2.43-5.01)$ & $3.01(2.08-4.36)$ \\
\hline \multicolumn{5}{|l|}{ Nicotine intake per day ${ }^{\#}$} \\
\hline $1-8$ mg/day & 290 & 34 & $2.46(1.60-3.78)$ & $2.33(1.51-3.59)$ \\
\hline $9-16$ mg/day & 418 & 38 & $2.38(1.57-3.61)$ & $2.11(1.38-3.21)$ \\
\hline$\geq 17 \mathrm{mg} /$ day & 537 & 58 & $3.68(2.53-5.36)$ & $3.16(2.15-4.65)$ \\
\hline
\end{tabular}

++ Reference category, * Model was adjusted for age (continuous) and survey (S1 or S2), model was additionally adjusted for alcohol consumption per day (0, 1$39, \geq 40 \mathrm{~g} /$ day), actual hypertension (yes or no), total cholesterol/HDL-C ratio $(<3.0,3.0-5.4, \geq 5.5$ ), physical inactivity (yes or no) and diabetes (no or yes), \# HRs and $95 \%$ Cls for ex- and occasional smokers from model including number of cigarettes smoked per day are displayed. The respective estimates in the models including tar yield, nicotine yield, tar or nicotine intake differ slightly and are almost equal.

Comparable associations with similar risk patterns were observed for nicotine intake per day.

\section{Risk of incident MI by number of cigarettes per day, tar and nicotine yield per cigarette}

Finally, we analysed the joint effect of the number of cigarettes and tar or nicotine yield per cigarette by defining four categories separately for men and women (Figure 1). With respect to tar yield, the lowest category consisted of smokers with a number of $\leq 19$ cigarettes smoked per day and with smoking cigarettes containing $\leq 12 \mathrm{mg}$ tar yield per cigarette. Correspondingly, the highest category comprised smokers consuming 20 or more cigarettes per day and with a tar yield of 13 or more mg per cigarette. As before, never-smokers comprised the reference category.

In both sexes, the risk of an incident MI was much higher for smokers with a high number of cigarettes per day $(\geq 20)$ and a high tar yield per cigarette $(\geq 13 \mathrm{mg}$ ) compared to the HRs of other three categories seen by a
HR of 3.06 (95\% CI 2.09-4.48) in men and 5.31 (95\% CI 2.00-14.07) in women in the multivariable-adjusted model. The HRs of low and high tar yield were very similar in the group with a number of $\leq 19$ cigarettes per day as both HRs were around 2.35. For the joint effect of the number of cigarettes and nicotine yield per cigarette, an analogous categorization was applied with a cut-off value of $0.8 \mathrm{mg}$ per cigarette and comparable results were observed.

\section{Discussion}

The present analysis based on a large population-based sample from Southern Germany shows a substantial MI risk increase in relation to the number of cigarettes smoked per day and adds important evidence of cumulative effects of tar and nicotine intake on the risk of an incident $\mathrm{MI}$ in both male and female regular smokers. A dose-response-association between high daily tar and nicotine intake and MI risk in both sexes could be observed. We found that in male regular smokers even 
Table 4 Risk of incident myocardial infarction by number of cigarettes per day (cig/day), tar and nicotine yield per cigarette (mg/cig) and tar and nicotine intake per day (mg/day) in women: Hazard ratio (HR) and $95 \%$ confidence interval $(95 \% \mathrm{Cl})$

\begin{tabular}{|c|c|c|c|c|}
\hline Smoking habits & $\begin{array}{l}\text { Number of } \\
\text { participants } \\
\text { (N) }\end{array}$ & $\begin{array}{l}\text { Number of } \\
\text { events } \\
\text { (N) }\end{array}$ & $\begin{array}{c}\text { Age- and survey-adjusted } \\
\text { model* } \\
\text { HR }(95 \% \mathrm{Cl})\end{array}$ & $\begin{array}{c}\text { MI risk factor-adjusted } \\
\text { model }^{+} \\
\text {HR }(95 \% \mathrm{Cl})\end{array}$ \\
\hline Never-smokers $^{++}$ & 2,613 & 49 & 1.00 & 1.00 \\
\hline Ex-smokers & 693 & 15 & $1.95(1.09-3.48)$ & $1.93(1.07-3.47)$ \\
\hline Occasional smokers & 139 & 2 & $1.56(0.38-6.44)$ & $1.60(0.39-6.65)$ \\
\hline \multicolumn{5}{|l|}{ Regular smokers } \\
\hline \multicolumn{5}{|l|}{ Number of cigarettes smoked per day } \\
\hline Light smokers (1 - 19 cig/day) & 480 & 8 & $1.83(0.86-3.90)$ & $1.68(0.79-3.57)$ \\
\hline Heavy smokers ( $\geq 20$ cig/day) & 272 & 6 & $3.76(1.57-8.97)$ & $3.86(1.57-9.50)$ \\
\hline \multicolumn{5}{|l|}{ Tar yield per cigarette ${ }^{\#}$} \\
\hline $1-12 \mathrm{mg} / \mathrm{cig}$ & 328 & 5 & $1.52(0.60-3.85)$ & $1.60(0.63-4.07)$ \\
\hline$\geq 13 \mathrm{mg} / \mathrm{cig}$ & 424 & 9 & $3.35(1.62-6.94)$ & $2.74(1.31-5.72)$ \\
\hline \multicolumn{5}{|l|}{ Nicotine yield per cigarette ${ }^{\#}$} \\
\hline $0.1-0.8 \mathrm{mg} / \mathrm{cig}$ & 300 & 5 & $1.58(0.63-3.98)$ & $1.67(0.66-4.24)$ \\
\hline$\geq 0.8 \mathrm{mg} / \mathrm{cig}$ & 452 & 9 & $3.22(1.55-6.68)$ & $2.63(1.26-5.50)$ \\
\hline \multicolumn{5}{|l|}{ Tar intake per day ${ }^{\#}$} \\
\hline $1-129 \mathrm{mg} /$ day & 324 & 4 & $1.27(0.46-3.54)$ & $1.31(0.47-3.65)$ \\
\hline 130 - 259 mg/day & 238 & 5 & $2.72(1.08-6.88)$ & $2.30(0.90-5.87)$ \\
\hline$\geq 260$ mg/day & 190 & 5 & $5.37(2.07-13.94)$ & $4.67(1.76-12.40)$ \\
\hline \multicolumn{5}{|l|}{ Nicotine intake per day ${ }^{\#}$} \\
\hline $1-8$ mg/day & 368 & 4 & $1.09(0.39-3.03)$ & $1.01(0.36-2.81)$ \\
\hline $9-16$ mg/day & 235 & 6 & $3.84(1.62-9.12)$ & $3.88(1.61-9.35)$ \\
\hline$\geq 17 \mathrm{mg} /$ day & 149 & 4 & $5.88(2.06-16.76)$ & $5.55(1.88-16.35)$ \\
\hline
\end{tabular}

++ Reference category, * Model was adjusted for age (continuous) and survey (S1 or S2), model was additionally adjusted for alcohol consumption per day (0, 1$19, \geq 20 \mathrm{~g} /$ day), actual hypertension (yes or no), total cholesterol/HDL-C ratio $(<3.0,3.0-5.4, \geq 5.5$ ), physical inactivity (yes or no) and diabetes (no or yes), \# HRs and $95 \% \mathrm{Cls}$ for ex- and occasional smokers from model including number of cigarettes smoked per day are displayed. The respective estimates in the models including tar yield, nicotine yield, tar or nicotine intake differ slightly and are almost equal.

a low or medium tar and nicotine intake per day revealed a substantial risk increase as compared to never-smokers. Risks were more pronounced in medium and high intake groups in female than in male regular smokers. The findings shown in this manuscript indicate that a reduction of tar and nicotine contents in cigarettes cannot be seen as a suitable public health policy in preventing the incidence of a MI.

Tobacco smoke contains more than 4,000 distinct components during the particulates and gas phase [17]. The toxic effects of tar and nicotine are widely understood. The toxins in tar are complex and contain several major carcinogens. Nicotine, however, is related to dopamine and other neurotransmitters that might sustain smokers' addiction [18]. Nicotine concentration largely determines the way in which a cigarette is smoked [17]. Both, tar and nicotine, contribute to the increased risk for cardiovascular disease among cigarette smokers [19]. Due to the regulation and legislation of reduction in tar and nicotine emissions, a new marketing strategy, which focuses on production of new cigarette brands with low yields, has developed by the tobacco industry. The strategy is directed towards the people who have become more aware of the health effects of smoking cigarettes, and also towards smoking behaviour among regular smokers. When smokers switch to low or ultra low yield cigarettes, many of them alter their smoking behaviours to maintain their usual intake of tar and nicotine; they might increase the number of puffs per cigarette, the volume of each puff, or the duration of each puff [11].

The effects of this modified cigarette design on risk of coronary heart disease have been investigated in several studies so far and the extent of the effects have remained contradictory [8-12,20,21]. Four hospital-based case-control studies revealed that switching to lower yield cigarettes is not an effective way of reducing tobacco related morbidity from myocardial infarction [8-11]. Another case-control study with survivors of a myocardial infarction in the United Kingdom showed that even low tar 


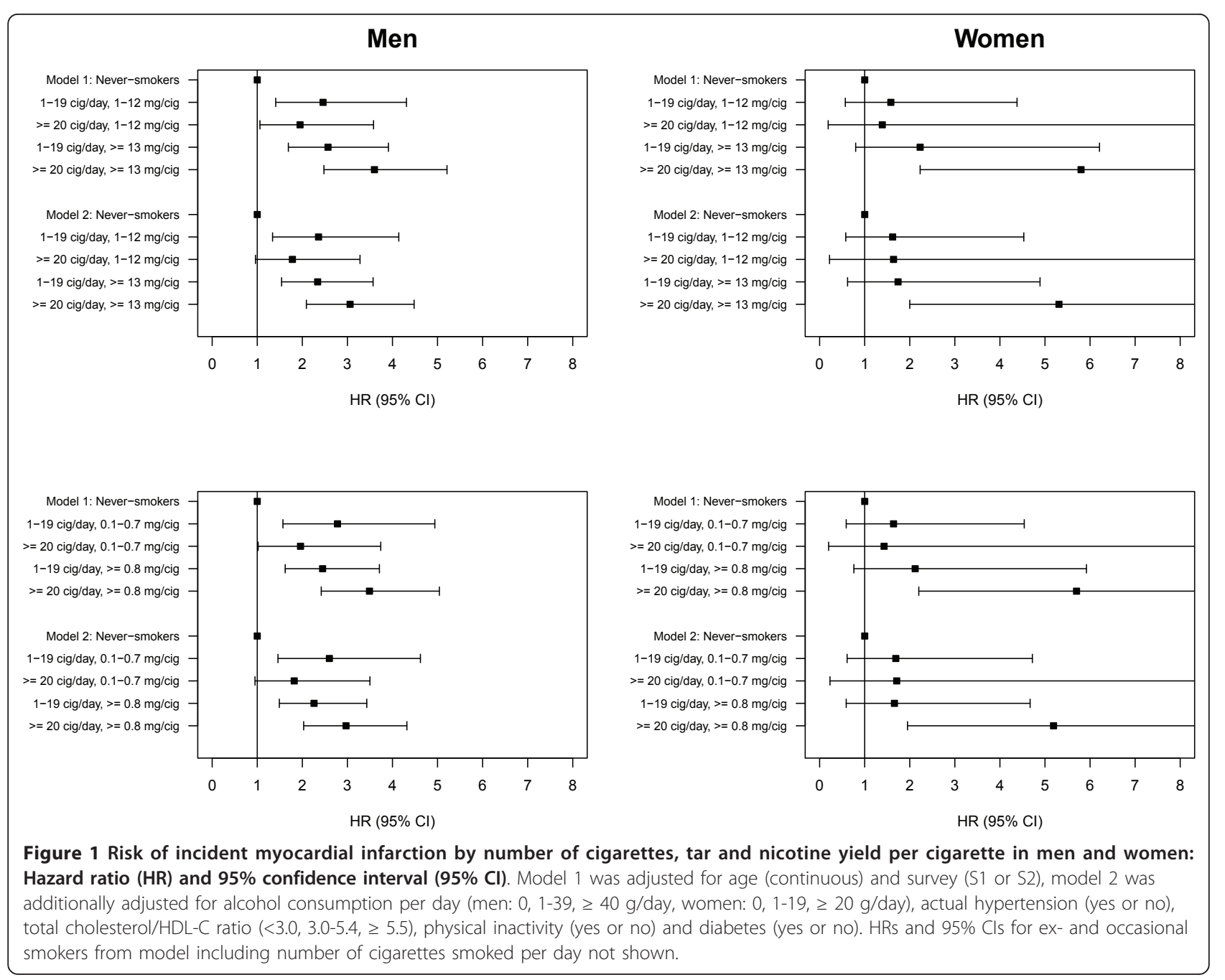

cigarettes still greatly increase rates of myocardial infarction [12]. However, a large British study based on a prospective epidemiological sample of four cohorts of men has reported that smoking of reduced tar yield cigarette might lead in a modest decreased overall mortality from smoking-related diseases [21].

In the present study, gender differences have been taken into account throughout all analyses. Only few studies have investigated the relative risk of smoking on the incidence of a MI event in both sexes within the same study population, presumably in part because of an insufficient number of female regular smokers. Our results showed that female regular smokers had higher MI risks than male regular smokers in medium and high categories of daily tar and nicotine intake. This result confirmed previous studies, which showed that women are more sensitive than men to some of the risky effects of smoking $[22,23]$. The sex-specific differences might be explained by more pronounced harmful effects of tobacco exposure in women compared to men
[23]. Moreover, a further explanation of the sex differences might be related to an interaction of sex hormones with components of the inhaled smoke. There is evidence that women who smoke are relatively deficient in oestrogen and possible biological mechanisms have been suggested [24-27].

Our study has several limitations which need to be mentioned. We could not consider effects of smoking inhalation patterns which might vary between smokers and therefore might affect tar or nicotine intake. These data were not assessed in the present study population. However, the daily cumulative concentrations of tar and nicotine in regular smokers may decrease the effects of different inhalation patterns. Moreover, we could not account for possible changes in cigarette brands and therefore possible changes in tar or nicotine intake during follow-up. However, it might be assumed that smokers choose mostly the same cigarette brand over the years and therefore that only a limited bias of the results might occur. 
Our study provided additional evidence for increasing risk of incident MI among male and female regular smokers in relation to tar and nicotine intake. Although the overall distribution of tar and nicotine yield per cigarette in the present study are somewhat lower than in former studies, associations between tar and nicotine yield per cigarette and the risk of an incident MI event were clearly visible.

\section{Conclusions}

The findings of the present study based on a large population-based sample add important evidence of the cumulative effects of tar and nicotine intake on risk of incident MI. Even low or medium yield cigarette intake increased substantially the risk of incident MI as compared to never-smokers. Therefore, reduction of tar and nicotine contents in cigarettes cannot be seen as a suitable public health policy in preventing myocardial infarction.

\section{Acknowledgements and Funding}

We thank all members of the Institutes of Epidemiology I and II and the field staff in Augsburg who were involved in the planning and conduct of the study. Moreover, we thank Cornelia Fiessler for creating the figure. The KORA research platform and the MONICA Augsburg studies were initiated and financed by the Helmholtz Zentrum München, German Research Center for Environmental Health, which is funded by the German Federal Ministry of Education, Science, Research and Technology and by the State of Bavaria. The MONICA Augsburg study was initiated and conducted by Prof. Ulrich Keil and his co-workers.

\section{Author details}

'Institute of Epidemiology II, Helmholtz Zentrum München, German Research Center for Environmental Health, Ingolstädter Landstrasse 1, 85764 Neuherberg, Germany. ${ }^{2}$ Institute of Epidemiology I, Helmholtz Zentrum München, German Research Center for Environmental Health, Ingolstädter Landstrasse 1, 85764 Neuherberg, Germany. ${ }^{3}$ Institute of Medical Informatics, Biometry and Epidemiology (IBE), Ludwig-Maximilians-Universität München, Marchioninistr. 15, 81377 München, Germany.

\section{Authors' contributions}

QLZ prepared the data, performed statistical analyses of the data, contributed to the interpretation of the findings and drafted the paper. JB performed statistical analyses of the data, contributed to the interpretation of the results and writing of the manuscript and performed the final editing of the manuscript. KHL commented on the interpretation of the findings. HEW supervised the study and revisited the paper critically. CM contributed to the interpretation of the findings and revised the paper critically. AD had the idea of the study, contributed to the statistical analysis of the data and commented on the interpretation of the results. All authors read and approved the final draft of the paper.

\section{Competing interests}

The authors declare that they have no competing interests.

Received: 26 October 2010 Accepted: 4 May 2011

Published: 4 May 2011

\section{References}

1. Doll R: Fifty years of research on tobacco. J Epidemiol Biostat 2000, 5:321-329.

2. Sasco AJ, Secretan MB, Straif $K$ : Tobacco smoking and cancer: a brief review of recent epidemiological evidence. Lung Cancer 2004, 45(Suppl 2):S3-9.
3. Jacobs DR Jr, Adachi H, Mulder I, Kromhout D, Menotti A, Nissinen A, Blackburn $\mathrm{H}$ : Cigarette smoking and mortality risk: twenty-five-year follow-up of the Seven Countries Study. Arch Intern Med 1999, 159:733-740.

4. Njolstad I, Arnesen E, Lund-Larsen PG: Smoking, serum lipids, blood pressure, and sex differences in myocardial infarction. A 12-year follow-up of the Finnmark Study. Circulation 1996, 93:450-456.

5. Keil U, Liese AD, Hense HW, Filipiak B, Döring A, Stieber J, Löwel H: Classical risk factors and their impact on incident non-fatal and fatal myocardial infarction and all-cause mortality in southern Germany. Results from the MONICA Augsburg cohort study 1984-1992. Monitoring Trends and Determinants in Cardiovascular Diseases. Eur Heart J 1998, 19:1197-1207.

6. Godtfredsen NS, Osler M, Vestbo J, Andersen I, Prescott E: Smoking reduction, smoking cessation, and incidence of fatal and non-fatal myocardial infarction in Denmark 1976-1998: a pooled cohort study. J Epidemiol Community Health 2003, 57:412-416.

7. World Health Organisation: Tobacco smoke and involuntary smoking. IARC Monographs 83. Lyon 2004.

8. Sauer WH, Berlin JA, Strom BL, Miles C, Carson JL, Kimmel SE: Cigarette yield and the risk of myocardial infarction in smokers. Arch Intern Med 2002, 162:300-306.

9. Kaufman DW, Helmrich SP, Rosenberg L, Miettinen OS, Shapiro S: Nicotine and carbon monoxide content of cigarette smoke and the risk of myocardial infarction in young men. N Engl J Med 1983, 308:409-413.

10. Negri E, Franzosi MG, La Vecchia C, Santoro L, Nobili A, Tognoni G: Tar yield of cigarettes and risk of acute myocardial infarction. GISSI-EFRIM Investigators. BMJ 1993, 306:1567-1570.

11. Palmer JR, Rosenberg $L$, Shapiro S: "Low yield" cigarettes and the risk of nonfatal myocardial infarction in women. N Engl J Med 1989, 320:1569-1573.

12. Parish S, Collins R, Peto R, Youngman L, Barton J, Jayne K, Clarke R, Appleby P, Lyon V, Cederholm-Williams S, Marshall J, Sleight P, for the International Studies of Infarct Survival (ISIS) Collaborators: Cigarette smoking, tar yields, and non-fatal myocardial infarction: 14,000 cases and 32,000 controls in the United Kingdom. The International Studies of Infarct Survival (ISIS) Collaborators. BMJ 1995, 311:471-477.

13. Löwel H, Döring A, Schneider A, Heier M, Thorand B, Meisinger C, for the MONICA/KORA Study Group: The MONICA Augsburg surveys-basis for prospective cohort studies. Gesundheitswesen 2005, 67(Suppl 1):S13-18, Review.

14. Tunstall-Pedoe H, Kuulasmaa K, Amouyel P, Arveiler D, Rajakangas AM, Pajak A: Myocardial infarction and coronary deaths in the World Health Organization MONICA Project. Registration procedures, event rates, and case-fatality rates in 38 populations from 21 countries in four continents. Circulation 1994, 90:583-612.

15. WHO MONICA Project. MONICA Manual, WHO Geneva, Cardiovascular Disease Unit. Geneva 1990.

16. Löwel H, Meisinger C, Heier M, Hörmann A: The population-based acute myocardial infarction (AMI) registry of the MONICA/KORA study region of Augsburg. Gesundheitswesen 2005, 67(Suppl 1):S31-37.

17. Stephens WE: Dependence of tar, nicotine and carbon monoxide yields on physical parameters: implications for exposure, emissions control and monitoring. Tob Control 2007, 16:170-176.

18. Benowitz NL: Clinical pharmacology of nicotine: implications for understanding, preventing, and treating tobacco addiction. Clin Pharmacol Ther 2008, 83:531-541, Review.

19. Hoffmann D, Hoffmann I: The changing cigarette, 1950-1995. J Toxicol Environ Health 1997, 50:307-364.

20. Thun MJ, Burns DM: Health impact of "reduced yield" cigarettes: a critical assessment of the epidemiological evidence. Tob Control 2001, 10(Suppl 1):i4-11.

21. Tang JL, Morris JK, Wald NJ, Hole D, Shipley M, Tunstall-Pedoe H: Mortality in relation to tar yield of cigarettes: a prospective study of four cohorts. BMJ 1995, 311:1530-1533.

22. Prescott E, Osler M, Andersen PK, Hein HO, Borch-Johnsen K, Lange P, Schnohr $\mathrm{P}$, Vestbo J: Mortality in women and men in relation to smoking. Int J Epidemiol 1998, 27:27-32.

23. Prescott $E$, Hippe M, Schnohr $P$, Hein HO, Vestbo J: Smoking and risk of myocardial infarction in women and men: longitudinal population study. BMJ 1998, 316:1043-1047. 
24. Grodstein F, Stampfer M: The epidemiology of coronary heart disease and estrogen replacement in postmenopausal women. Prog Cardiovasc Dis 1995, 38:199-210.

25. Stampfer MJ, Colditz GA, Willett WC, Manson JE, Rosner B, Speizer FE, Hennekens CH: Postmenopausal estrogen therapy and cardiovascular disease. Ten-year follow-up from the nurses' health study. N Engl J Med 1991, 325:756-762

26. Baron JA, Vecchia CL, Levi F: The antiestrogenic effect of cigarette smoke in women. Am J Obstet Gynecol 1990, 162:502-514.

27. Michnovicz JJ, Hershcopf RJ, Naganuma H, Bradlow HL, Fishman J: Increased 2- hydroxylation of estradiol as a possible mechanism for the anti-estrogenic effect of cigarette smoking. N Engl J Med 1986, 315:1305-1309.

\section{Pre-publication history}

The pre-publication history for this paper can be accessed here: http://www.biomedcentral.com/1471-2458/11/273/prepub

doi:10.1186/1471-2458-11-273

Cite this article as: Zhang et al:: Association of daily tar and nicotine intake with incident myocardial infarction: Results from the populationbased MONICA/KORA Augsburg Cohort Study 1984 - 2002. BMC Public Health 2011 11:273.

\section{Submit your next manuscript to BioMed Central} and take full advantage of:

- Convenient online submission

- Thorough peer review

- No space constraints or color figure charges

- Immediate publication on acceptance

- Inclusion in PubMed, CAS, Scopus and Google Scholar

- Research which is freely available for redistribution

Submit your manuscript at www.biomedcentral.com/submit 